\title{
Could nanoparticles that mimic the NADPH oxidase be used to kill tumor cells?
}

First draft submitted: 5 May 2016; Accepted for publication: 10 May 2016; Published online: 27 June 2016

Keywords: cancer $\bullet$ nanomedicine $\bullet$ reactive oxygen species

The NADPH oxidase is a membrane-bound enzyme of leukocytes that produces reactive oxygen species (ROS) at the expense of cytoplasmic NADPH during immunologic and inflammatory responses. We have found that the chemical reactions of $\mathrm{WO}_{3} / \mathrm{Pt}$ nanoparticles mimic those of the NADPH oxidase. We therefore suggest that $\mathrm{WO}_{3} / \mathrm{Pt}$ nanoparticles can augment or replace this functional attribute of immune effector cells. We further propose that these artificial immune-like responses can be used to kill tumor cells.

\section{Reactive oxygen species}

ROS include hydrogen peroxide $\left(\mathrm{H}_{2} \mathrm{O}_{2}\right)$, superoxide anions $\left(\mathrm{O}_{2}^{-}\right)$, singlet oxygen $\left({ }^{1} \mathrm{O}_{2}\right)$ and hydroxyl radicals $\left({ }^{\circ} \mathrm{OH}\right)$. They play a key role in host defense against infectious agents and tumors [1-4]. The NADPH oxidase, a multisubunit enzyme, catalyzes the reaction:

$\mathrm{NADPH}+2 \mathrm{O}_{2} \rightarrow \mathrm{NADP}^{+}+2 \mathrm{O}_{2}^{-}+\mathrm{H}^{+}$

Electrons are escorted across cell membranes by a transmembrane cytochrome-containing protein. Superoxide anions produced by the NADPH oxidase contribute to the downstream formation of other ROS, including hydrogen peroxide and hydroxyl radicals. In addition to endogenous biological mechanisms, exogenous agents also contribute to ROS formation in vivo. For example, over half of the US FDA approved anticancer drugs produce ROS in vivo [5].

Moreover, radiation therapy, photodynamic therapy (PDT) and certain cytokine therapies for cancer promote ROS synthesis [5-9]. Thus, ROS are produced by multiple mechanisms that lead to oxidative stress and cell death.

One specific application of ROS production in vivo is in the PDT of cancer (for a review see $[10])$. In this application, a photosensitizer is injected intravenously, intracamerally, or intralesionally into a patient. Photosensitizers in clinical use are small organic molecules that tend to accumulate in tumors, although other tissues are often affected. When photosensitizers absorb light, they are capable of producing ROS, such as singlet oxygen. Singlet oxygen reacts with nearby biomolecules, thus damaging the targeted tumor cells. PDT is used to treat ocular cancer, bladder cancer, stomach cancer, non-small-cell lung cancer, esophageal cancer, stomach cancer, cervical cancer and head and neck cancer [10]. One important limitation found for organic photosensitizers is that they are photobleached during therapy, which can last only a few minutes. We have recently introduced another approach in PDT that relies upon the catalytic activity of $\mathrm{WO}_{3} / \mathrm{Pt}$ nanoparticles [11,12], which addressed this and other issues encountered in conventional PDT.

\section{$\mathrm{WO}_{3} / \mathrm{Pt}$ nanoparticles}

The physical and chemical properties of $\mathrm{WO}_{3} / \mathrm{Pt}$ nanoparticles have been described by Abe et al. [13] and Kim et al. [14]. We have extended their work by developing $\mathrm{WO}_{3} / \mathrm{Pt}$

\section{Howard R Petty}

Department of Ophthalmology \& Visual Sciences, 1000 Wall Street, University of Michigan Medical School, Ann Arbor, MI 48105, USA

Tel.: +1 7346470384

hpetty@umich.edu 
nanoparticles specifically tailored to use in PDT [11,12]. $\mathrm{WO}_{3} / \mathrm{Pt}$ nanoparticles were prepared by photodeposition. The $\mathrm{WO}_{3}$ semiconductor absorbs visible light, thus creating an excited state electron and a hole within the matrix. The hole migrates to the nanoparticle's surface where it abstracts an electron from surrounding molecules such as amino acids, carbohydrates, metabolites as well as the electron carrier NADPH. Hydroxyl radicals attack organic molecules via addition reactions and abstraction reactions. The excited state electrons accumulate at sites of $\mathrm{Pt}$ photodeposition. The $\mathrm{Pt}$ photocathode traps electrons, thus reducing electronhole recombination. Importantly, these electrons promote the reduction of molecular oxygen to hydroxyl radicals, a highly toxic ROS. Hydroxyl radicals are uncharged, highly reactive molecules that are soluble in both aqueous and membrane phases. They can abstract a hydrogen atom from an unsaturated lipid to form a lipid radical, which activates the lipid peroxidation pathway (LPP). The autocatalytic LPP amplifies the effect of lipid radicals (Figure 1) leading to the production of toxic aldehydes, membrane disruptive lipid hydroperoxides, lysosome leakage, apoptotic signals and additional toxic molecules (Figure 1). Illumination of $\mathrm{WO}_{3} / \mathrm{Pt}$ nanoparticles promotes both apoptotic and necrotic cell death.

As mentioned above, the $\mathrm{WO}_{3}$ photoanode reacts with multiple biomolecules. Previous studies have characterized the physical interaction of $\mathrm{WO}_{3}$ nanoparticles with organophosphorous compounds [15]. Not surprisingly, NADPH, a organic molecule contain- ing phosphorous, is an excellent substrate for $\mathrm{WO}_{3} / \mathrm{Pt}$ nanoparticles using both purified reactants and intact living cells [12]. This observation has profound biological implications because several key host anti-oxidant defense systems require NADPH. NADPH is required for the regeneration of reduced glutathione [16], which clears toxins such as lipid radicals and lipid hydroperoxides from cells. These effects, however, extend beyond the glutathione system. NADPH-dependent aldehyde reductases are used to remove highly reactive aldehydes from cells. Intramembrane quinones $\left(\mathrm{QH}_{2}\right)$ are an important intramembrane anti-oxidant, whose production is driven by NADPH $[17,18]$. Thus, $\mathrm{WO}_{3} / \mathrm{Pt}$ nanoparticles provide a dramatic 1-2 punch to tumor cells with the photoanode creating carbon-centered radicals and deactivating NADPH-dependent antioxidative pathways while the photocathode produces hydroxyl radicals. The overall process is illustrated schematically in Figure 1. Illuminated $\mathrm{WO}_{3} / \mathrm{Pt}$ nanoparticles have been found to activate the LPP and kill tumor cells in vitro [11]. When tested in an in vivo model of breast cancer metastasis to the eye, these nanoparticles performed better than conventional chemotherapies using the same tumor cell line [12].

\section{Therapeutic advantages of $\mathrm{WO}_{3} / \mathrm{Pt}$ nanoparticles}

$\mathrm{WO}_{3} / \mathrm{Pt}$ nanoparticles have numerous technical and therapeutic advantages that are summarized in Box 1. These nanoparticles are capable of producing large amounts of hydroxyl radicals. These ROS are pro-

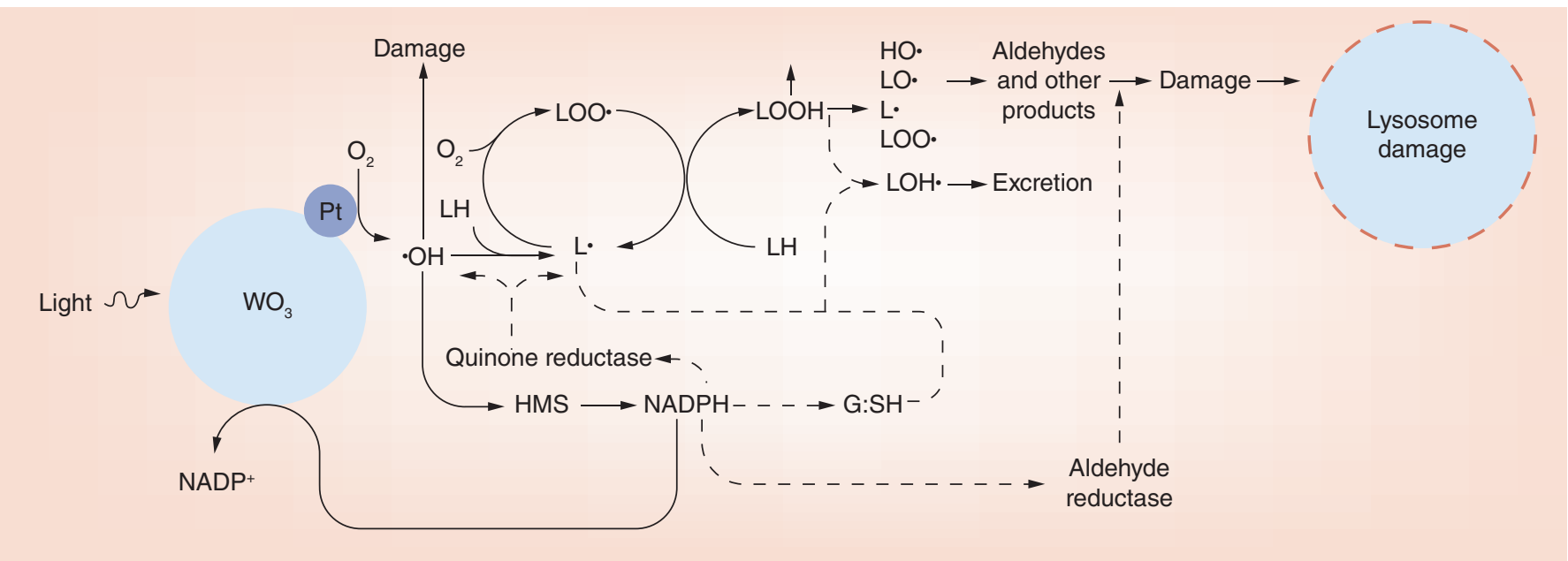

Figure 1. A schematic diagram of nanoparticle action within cells is shown. The photocathodes of $\mathrm{WO}_{3} / \mathrm{Pt}$ nanoparticles generate hydroxyl radicals. Hydroxyl radicals damage cell components, including lipids, which activate the lipid peroxidation pathway. Covalently modified lipids and their downstream products damage cells, including the lysosomal membrane. These processes activate cell death pathways. The photoanode of $\mathrm{WO}_{3} / \mathrm{Pt}$ nanoparticles uses multiple organic molecules as electron donors, including the 'professional' electron donor NADPH. By scavenging electrons from NADPH, NADPH-dependent cellular anti-oxidant pathways are blunted or blocked. These NADPH-dependent pathways include the glutathione pathway, the aldehyde reductase pathway and the quinone reductase pathway. (Pathways promoting cell death are shown using solid lines whereas pathways deflecting cell damage are shown as dashed lines.) 
duced at the expense of cellular molecules, including the oxidation of the electron donor NADPH. Thus, $\mathrm{WO}_{3} / \mathrm{Pt}$ nanoparticles have the unique advantage of lowering cellular anti-oxidant defenses by utilizing NADPH while simultaneously producing hydroxyl radicals. The toxicity of $\mathrm{WO}_{3} / \mathrm{Pt}$ nanoparticles is likely to be minimal. The $\mathrm{LD}_{50}$ of $\mathrm{WO}_{3}$ is $1059 \mathrm{mg} / \mathrm{kg}$ making it safer than aspirin or caffeine. As the functional components of the nanoparticles are inorganic, and are mimicking an endogenous enzyme system, we anticipate that they will be less likely to exhibit harmful drug-drug interactions in vivo. In contrast to the biological NADPH oxidase, nanoparticles remain effective at low $\mathrm{pH}$. In the biological system, leukocyte activation to produce superoxide anions requires $\mathrm{I}_{\mathrm{CRAC}}$ (calcium release-activated current)-mediated calcium signaling, which is $\mathrm{pH}$ sensitive. Moreover, ROS production by leukocytes is transient, as leukocytes may damage themselves. In contrast $\mathrm{WO}_{3} / \mathrm{Pt}$ nanoparticles are highly stable, and resistant to ROS-mediated damage. As such, $\mathrm{WO}_{3} / \mathrm{Pt}$ nanoparticles are resistant to photobleaching, which is a major problem with conventional organic photosensitizers. Finally, the photosensitizers in use today accumulate at tumor cells, but do not specifically tag tumor cells. In contrast, $\mathrm{WO}_{3} / \mathrm{Pt}$ nanoparticles can be specifically tag breast cancer cells when modified to express folate groups [Ретту H ET AL., Unpublished data]. Thus, $\mathrm{WO}_{3} / \mathrm{Pt}$ nanoparticles have numerous advantages.

\section{Market acceptance}

Although there are many therapeutic advantages of nanotherapies, this will not be the primary factor driving nanotherapeutics into the marketplace. One important factor influencing the marketability of nanoparticles is their cost of synthesis. A four step synthesis of a nanoparticle is far less expensive that a 22 step synthesis of a conventional organic pharmaceutical. Another factor affecting market entry is the availability of market space. If a company has a competing organic phar- maceutical, they will not be interested in bringing a competing nanotherapeutic to market. The best strategy to find market space is to identify a company with expiring patents for a conventional pharmaceutical treating the same indication as the nanoparticle under development. The nanoparticle must be protected by patents. According to the Tufts Center for the Study of Drug Development, bringing a new pharmaceutical to market costs roughly US $\$ 2.8$ billion in 2016 (in 2013 dollars), which includes the cost of capital [19]. Thus, manufacturers would not be able to recoup their expenses without patent protection. Another avenue to accelerate market entry is to use the nanoparticle to treat an orphan disease. As the regulatory barriers for market entry are lower for pharmaceuticals addressing orphan diseases, the costs of regulatory approval and clinical trials are much lower, as was the case for Gleevec $^{\circledR}$. Last but not least, one must also consider the customer. In the case of PDT, the customer is the physician. In the case of the nanoparticles described above, their lack of photobleaching makes them very attractive to physicians as they can better control patient treatment.

\section{Outlook}

Broadly, the outlook of nanotechnology in medicine is very bright, as the nanomedicine marketplace should experience a $12.3 \%$ compound annual growth rate and reach US $\$ 177.6$ billion by 2019 [20]. In the present article, we have focused on $\mathrm{WO}_{3} / \mathrm{Pt}$ nanoparticles, an NADPH oxidase biomimetic that uses NADPH to synthesize ROS. The key requisite factors, efficacy, cost, safety, marketability, consumer advantages all support a future clinical role for these nanoparticles. We anticipate that doping the semiconductor matrix with other elements can be used to extend the absorption properties of these photosensitizers into the red, thereby extending their use to deeper tissue sites. These nanoparticles could be targeted to other sites or used in other indications by using different ligands.

\section{Box 1. Summary of expected advantages of $\mathrm{WO}_{3} / \mathrm{Pt}$ nanoparticles in photodynamic therapy.}

- Photocathode produces ${ }^{\circ} \mathrm{OH}$ radicals, a highly reactive ROS that leads to cell death

- Photoanode abstracts electrons from biomolecules, including NADPH:

- Leads to disrupted biomolecules

- Loss of NADPH reduces a tumor cell's ability to mount an anti-oxidative defense mediated by:

- The NADPH-dependent synthesis of reduced glutathione

- The NADPH-dependent catalytic actions of aldehyde reductases and quinone reductases

- Inorganic composition makes drug-drug interactions less likely

- $\mathrm{LD}_{50}=1059 \mathrm{mg} / \mathrm{kg}$ for $\mathrm{WO}_{3}$

- Functional over a broad range of $\mathrm{pH}$ values

- $\mathrm{WO}_{3}$ has a narrow-band gap, thus permitting excitation with visible light

- These inorganic nanoparticles do not photobleach during illumination, as do conventional organic dyes, thus putting the surgeon in control of exposure 
As an example, one could deliver these nanoparticles to bacteria using siderophores. Additional cross-talk between the physical and medical sciences is anticipated to yield further improvements in these metal/ metal oxide nanoparticles. As $\mathrm{WO}_{3} / \mathrm{Pt}$ nanoparticles have numerous advantages at the beginning of their development cycle, we anticipate further improvements in their performance and their broad use in PDT.

\section{References}

1 Clark RA, Klebanoff SJ. Neutrophil-mediated tumor cell cytotoxicity: role of the peroxidase system. J. Exp. Med. 141, 1442-1447 (1975).

2 Ackermann MF, Lamm KR, Wiegand GW, Luster MI. Antitumor activity of murine neutrophils demonstrated by cytometric analysis. Cancer Res. 49, 528-532 (1989).

3 Roos D, van Bruggen R, Meischl C. Oxidative killing of microbes by neutrophils. Microbes Infect. 5, 1307-1315 (2003).

4 Kobayashi SD, Voyich JM, DeLeo FR. Regulation of the neutrophil-mediated inflammatory response to infection. Microbes Infect. 5, 1337-1344 (2003).

5 Chen Y, Jungsuwadee P, Vore M, Butterfield DA, St Clair DK. Collateral damage in cancer chemotherapy: oxidative stress in nontargeted tissues. Mol. Interv. 7, 147-156 (2007).

6 Yamauchi N, Kuriyama H, Watanabe N, Neda H, Maeda M, Niitsu Y. Intracellular hydroxyl radical production induced by recombinant human tumor necrosis factor and its implication in the killing of tumor cells in vitro. Cancer Res. 49, 1671-1675 (1989).

7 Riley PA. Free radicals in biology: oxidative stress and the effects of ionizing radiation. Int. J. Radiat. Biol. 65, 27-33 (1994).

8 Doroshow JH. Role of hydrogen peroxide and hydroxyl radical formation in the killing of Ehrlich tumor cells by anticancer quinones. Proc. Natl Acad. Sci. USA 83, 4514-4518 (1986).

9 Hubenak JR, Zhang Q, Branch CD, Kronowitz SJ. Mechanisms of injury to normal tissue after radiotherapy: a review. Plast. Reconstr. Surg. 133, e49-e56 (2014).

10 Dolmans DE, Fukumura D, Jain RK. Photodynamic therapy for cancer. Nat. Rev. Cancer 3, 380-387 (2003).
Financial \& competing interests disclosure HR Petty is the inventor of a patent on this topic owned by the Regents of the University of Michigan. The author has no other relevant affiliations or financial involvement with any organization or entity with a financial interest in or financial conflict with the subject matter or materials discussed in the manuscript apart from those disclosed.

No writing assistance was utilized in the production of this manuscript.

11 Clark AJ, Petty HR. $\mathrm{WO}_{3} / \mathrm{Pt}$ nanoparticles promote lightinduced lipid peroxidation and lysosomal instability within tumor cells. Nanotechnology 27, 075103 (2016).

12 Clark AJ, Coury EL, Meilhac AM, Petty HR. $\mathrm{WO}_{3} / \mathrm{Pt}$ nanoparticles are NADPH oxidase biomimetics that mimic effector cells in vitro and in vivo. Nanotechnology 27, 065101 (2016).

13 Abe R, Takami H, Murakami N, Ohtani B. Pristine simple oxides as visible light driven photocatalysts: highly efficient decomposition of organic compounds over platinum-loaded tungsten oxide. J. Am. Chem. Soc. 130, 7780-7781 (2008).

14 Kim J, Lee CW, Choi W. Platinized $\mathrm{WO}_{3}$ as an environmental photocatalyst that generates $\mathrm{OH}$ radicals under visible light. Environ. Sci. Technol. 44, 6849-6854 (2010).

15 Kim CS, Lad RJ, Tripp CP. Interaction of organophosphorous compounds with $\mathrm{TiO}_{2}$ and $\mathrm{WO}_{3}$ surfaces probed by vibrational spectroscopy. Sensors Actuators $B 76$, 442-448 (2001).

16 Carlberg I, Mannervik B. Glutathione reductase. Methods Enzymol. 113, 484-490 (1985).

17 Vasukuou V, Ross D, Nebert DW. Update of the NAD(P) $\mathrm{H}$ :Quinone oxidoreductase (NQO) gene family. Hum. Genomics 2, 329-335 (2006).

18 Jin Y, Penning TM. Aldo-keto reductases and bioactivation/ detoxication. Ann. Rev. Pharmacol. Toxicol. 47, 263-292 (2007).

19 DiMasi JA, Grabowski HG, Hansen RW. Innovation in the pharmaceutical industry: New estimates of R\&D costs. J. Health Econ. 47, 20-33 (2016).

20 Transparency Marker Research: Global Nanomedicine Market: Increased Research Collaborations to Drive Market in Asia Pacific at $14.6 \%$ CAGR. www.transparencymarketresearch.com 